OPEN ACCESS

Edited by:

Jian Su,

Nanjing University of Science and

Technology, China

Reviewed by:

Biing-Chiau Tzeng,

National Chung Cheng University,

Taiwan

Mani Govindasamy,

National Taipei University of

Technology, Taiwan

Fangna Dai,

China University of Petroleum, China

*Correspondence:

Hai-Ying Wang

wanghaiying@nju.edu.cn

Jian-Ping $\mathrm{Ma}$

xxgk123@163.com

Guang-Xiang Liu

njuliugx@126.com

Jing-Yuan Ge

gejingyuan90@126.com

tThese authors have contributed equally to this work

Specialty section: This article was submitted to Inorganic Chemistry, a section of the journal

Frontiers in Chemistry

Received: 30 September 2021 Accepted: 04 November 2021 Published: 29 November 2021

Citation:

Hu Q, Qin J, Wang X-F, Ran G-Y, Wang Q, Liu G-X, Ma J-P, Ge J-Y and

Wang $\mathrm{H}-\mathrm{Y}$ (2021) Cu-Based Conductive MOF Grown in situ on $\mathrm{Cu}$ Foam as a Highly Selective and Stable

Non-Enzymatic Glucose Sensor.

Front. Chem. 9:786970.

doi: 10.3389/fchem.2021.786970

\section{Cu-Based Conductive MOF Grown in situ on Cu Foam as a Highly Selective and Stable Non-Enzymatic Glucose Sensor}

\author{
Qin $\mathrm{Hu}^{1 \dagger}$, Jie Qin ${ }^{2 \dagger}$, Xiao-Feng Wang ${ }^{3}$, Guang-Ying Ran ${ }^{1}$, Qiang Wang ${ }^{1}$, Guang-Xiang Liu ${ }^{3 *}$, \\ Jian-Ping $\mathrm{Ma}^{4 *}$, Jing-Yuan $\mathrm{Ge}^{5 *}$ and Hai-Ying Wang ${ }^{1,3 *}$ \\ ${ }^{1}$ College of Chemistry and Materials Science, Sichuan Normal University, Chengdu, China, ${ }^{2}$ School of Life Sciences and \\ Medicine, Shandong University of Technology, Zibo, China, ${ }^{3}$ School of Environmental Science, Nanjing Xiaozhuang University, \\ Nanjing, China, ${ }^{4}$ School of Chemistry, Chemical Engineering and Materials Science, Shandong Normal University, Jinan, China, \\ ${ }^{5}$ College of Chemistry and Materials Engineering, Wenzhou University, Wenzhou, China
}

A non-enzymatic electrochemical sensor for glucose detection is executed by using a conductive metal-organic framework (MOF) Cu-MOF, which is built from the 2,3,6,7,10,11-hexahydroxytriphenylene (HHTP) ligand and copper acetate by hydrothermal reaction. The Cu-MOF demonstrates superior electrocatalytic activity for glucose oxidation under alkaline $\mathrm{pH}$ conditions. As an excellent non-enzymatic sensor, the Cu-MOF grown on Cu foam (Cu-MOF/CF) displays an ultra-low detection limit of $0.076 \mu \mathrm{M}$ through a wide concentration range $(0.001-0.95 \mathrm{mM})$ and a strong sensitivity of 30,030 $\mathrm{mA} \mu \mathrm{M}^{-1} \mathrm{~cm}^{-2}$. Overall, the Cu-MOF/CF exhibits a low detection limit, high selectivity, excellent stability, fast response time, and good practical application feasibility for glucose detection and can promote the development of MOF materials in the field of electrochemical sensors.

Keywords: non-enzymatic, electrochemical sensor, glucose, MOF, redox activity

\section{INTRODUCTION}

Glucose is the direct source of energy for the human body and is indispensable for human functional movement. However, abnormal glucose concentration such as hypoglycemia and diabetes can lead to death and disability (Pandey et al., 2011). Therefore, the detection of glucose is of great significance to human health. Over the past few decades, many techniques have been used to detect glucose in human blood, such as colorimetry (Liu et al., 2011), gas chromatography (Larsen, 2015), fluorescence (Xie et al., 2017), and electrochemical sensors (Lpa et al., 2019; Xu et al., 2021). Among them, the accuracy of colorimetry is poor, the gas chromatography equipment is complex and expensive (Feng et al., 2016; Hui and Ying, 2017; Wang et al., 2020), and the fluorescence is very sensitive to some interfering substances (Zheng et al., 2019). Compared with enzyme electrochemical sensors, the nonenzymatic electrochemical sensor has the advantages of long service life, high cost performance, excellent stability, simple operation, and easy to carry (Clark and Lyons, 2010; Hui et al., 2016; Hui et al., 2017; Zhang et al., 2017; Archana et al., 2019; Zhao et al., 2020). Above all, it is very necessary to develop a non-enzymatic sensor with excellent performance (Hua et al., 2016; Niu et al., 2016).

Metal-organic frameworks (MOFs) are a family of novel porous crystalline materials composed of organic linkers and inorganic metal ions/clusters and have attracted wide attention for their potential applications in many fields (Hmadeh et al., 2012; Chandran et al., 2017), such as catalysis, 


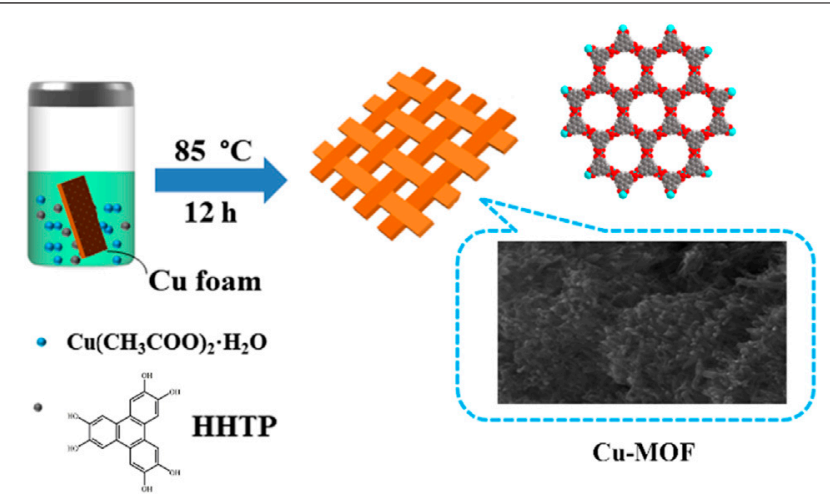

SCHEME 1 | Structure and synthetic process of Cu-MOF.

gas storage and separation, and energy storage and conversion (Adil et al., 2017; Doonan et al., 2017; Stassen et al., 2017; Wang et al., 2018). In recent years, MOFs and their derivatives have been considered promising candidates for electrochemical sensors due to their structure adjustability and fascinating properties, such as high surface area, flexible pore size, exposed active sites, and chemical stability (Hou et al., 2013; Wang et al., 2013). However, the low conductivity of most primitive MOFs limits their application in electrochemical sensing (Wei and Yin, 2015; Usman et al., 2016; Kanj et al., 2019). The common solutions to improve the conductivity of materials are coupling MOFs with conductive materials such as carbon black and electroconductive rubber. However, these methods not only increase the series resistance but also lead to reduction in the surface area, blocking the active sites and hindering the diffusion of target molecules (Zhu et al., 2016; Ko et al., 2018). Therefore, it still remains a huge challenge to prepare pristine MOFs as efficient electrocatalysts for glucose oxidation. Triphenylene (TP) is a planar-conjugated polycyclic aromatic hydrocarbon, and the organic ligands containing the TP unit can be used as starting material to construct novel multifunctional MOF materials and covalent organic frameworks (COFs) (Hmadeh et al., 2012). Some MOFs based on the TP ligand not only exhibit good conductivity but also exhibit remarkably catalytic performance (Hmadeh et al., 2012; Zhao et al., 2017; Cheng et al., 2019; Liu et al., 2019; Shi et al., 2020; Hu et al., 2021; Xu et al., 2021).

In this study, we developed a high-performance nonenzymatic electrochemical glucose sensor by in situ growth of conductive copper MOF on copper foam (CF) using a simple one-step hydrothermal method. Under the optimal conditions of each parameter value, the prepared electrode $\mathrm{Cu}-\mathrm{MOF} / \mathrm{CF}$ showed excellent electrocatalytic activity for glucose oxidation at alkaline $\mathrm{pH}$ with high sensitivity, low detection limit, wide linear detection range, short response time, and excellent stability. Moreover, the results of the human serum test showed that the material had good practical application feasibility.

\section{EXPERIMENTAL SECTIONS}

\section{Physical Measurements}

A Bruker D8 Advance X-ray diffractometer equipped with $\mathrm{Cu}-\mathrm{Ka}$ radiation $(\lambda=1.5418 \AA$ ) was used to collect powder X-ray diffraction (PXRD) data at room temperature. Calculated PXRD patterns were generated using Mercury 3.0 (Zhao et al., 2015; Su et al., 2017). Scanning electron microscopy (SEM) images were obtained on a Hitachi SU8010 SEM at $15 \mathrm{kV}$ with energy-dispersive X-ray (EDX). Transmission electron microscopy (TEM) measurements were carried out on a Bruker EMX 10/12. X-ray photoelectron spectroscopy (XPS) was performed on Thermo ESCALAB 250XI with aluminum$\mathrm{Ka}$ radiation.

\section{Materials and Syntheses}

All starting materials were commercially available and were used without further purification. Sodium hydroxide $(\mathrm{NaOH})$, copper (II) acetate monohydrate $\left(\mathrm{Cu}\left(\mathrm{CH}_{3} \mathrm{COO}\right)_{2} \cdot \mathrm{H}_{2} \mathrm{O}\right)$, glucose $(\mathrm{Glu})$, sodium chloride $(\mathrm{NaCl})$, ascorbic acid (AA), lactose (Lac), uric acid (UA), fructose (Fru), and dopamine (DA) were purchased from Aladdin Ltd. (Shanghai, China). Human serum samples were purchased from Nanjing Bonason Biological Technology Co., Ltd. (The experiment complies with relevant ethical principles and participants agreed and knew the content of the experiment.) All reagents were used as received without further purification. Water used in this experiment was deionized water. 2,3,6,7,10,11-hexahydroxytriphenylene (HHTP) is prepared according to the literature method (Hmadeh et al., 2012).

Preparation of $\mathrm{Cu}-\mathrm{MOF} / \mathrm{CF}$. $\mathrm{Cu}-\mathrm{MOF} / \mathrm{CF}$ was prepared using a facile one-step hydrothermal method (Scheme 1). CF was pre-cleaned by ultrasonicating sequentially in acetone, ethanol, and water for $15 \mathrm{~min}$. HHTP $(0.03 \mathrm{mmol}, 7 \mathrm{mg})$ and $\mathrm{Cu}\left(\mathrm{CH}_{3} \mathrm{COO}\right)_{2} \cdot \mathrm{H}_{2} \mathrm{O}(0.08 \mathrm{mmol}, 10 \mathrm{mg})$ were dissolved in $\mathrm{H}_{2} \mathrm{O}$ $(4 \mathrm{ml})$. The mixture and the pretreated CF were placed in a $20-\mathrm{ml}$ glass bottle and heated at $85^{\circ} \mathrm{C}$ for $12 \mathrm{~h}$.

\section{Electrochemical Measurements}

A CHI 660E (Chenhua, Shanghai) electrochemical workstation was used to conduct all electrochemical measurements at room 


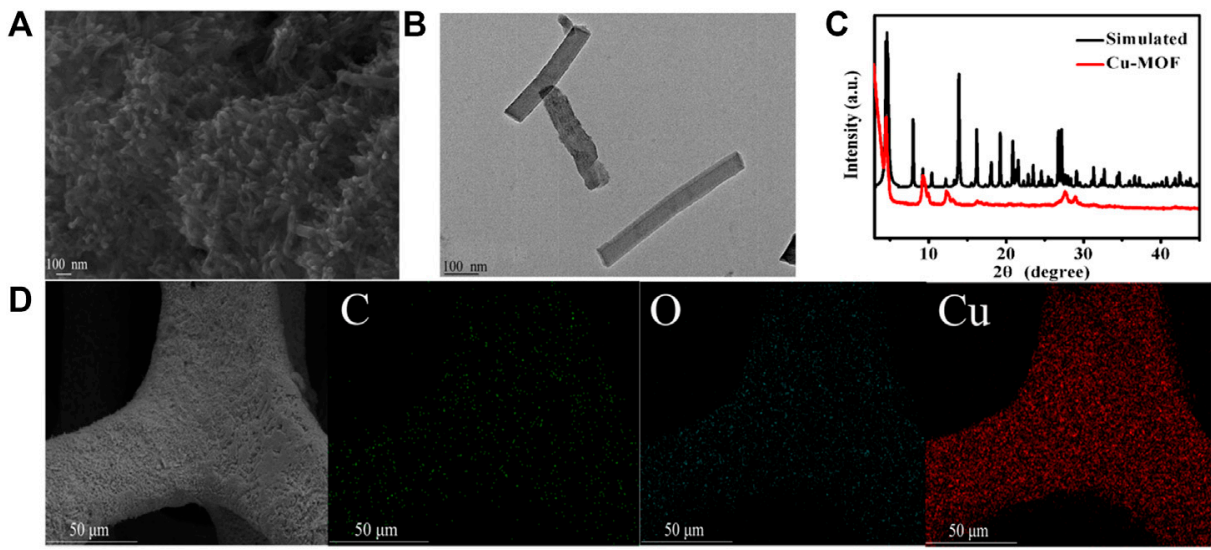

FIGURE 1 | (A) SEM image of Cu-MOF/CF. (B) TEM figure of Cu-MOF. (C) PXRD pattern of the as-synthesized Cu-MOF. (D) SEM and EDX elemental mapping images of $\mathrm{C}, \mathrm{O}$, and $\mathrm{Cu}$ for $\mathrm{Cu}-\mathrm{MOF} / \mathrm{CF}$.
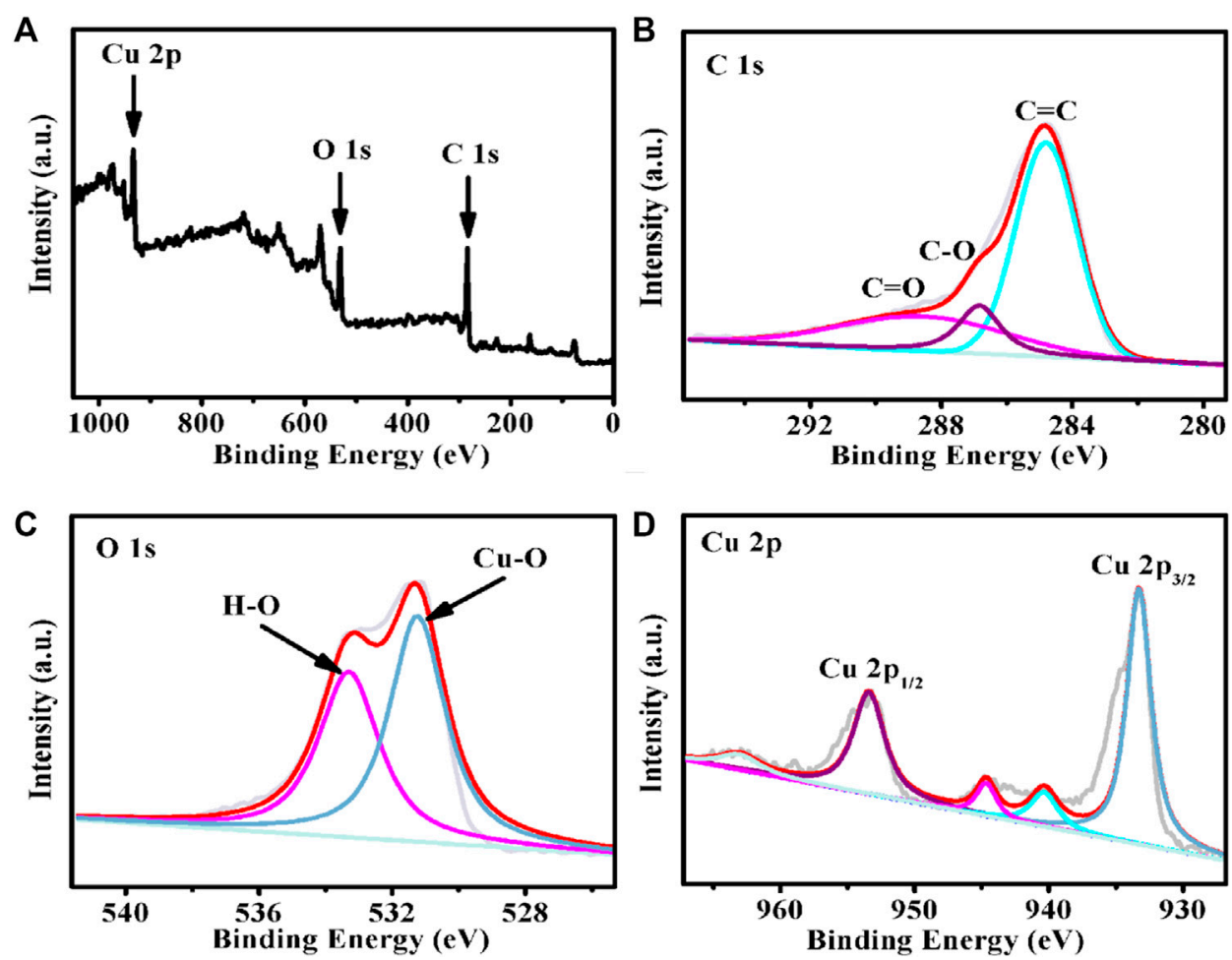

FIGURE 2 | XPS spectrum for the Cu-MOF: (A) survey spectrum (B) C 1s, (C) O 1s, and (D) Cu 2p.

temperature. The test was conducted using a three-electrode system: a platinum wire was used as the counter electrode, a mercuric oxide electrode $(\mathrm{Hg} / \mathrm{HgO})$ was used as the reference electrode, and the as-prepared $\mathrm{Cu}-\mathrm{MOF} / \mathrm{CF}$ was used as the working electrode. In addition, the geometric area of working electrodes was controlled at $0.2 \times 0.2 \mathrm{~cm}^{-2}$ in all tests (Supplementary Scheme S1).

\section{RESULT AND DISCUSSION}

\section{Material Characterization}

The SEM image of Cu-MOF/CF (Figure 1A) and TEM image for sample obtained by sonicating $\mathrm{Cu}-\mathrm{MOF} / \mathrm{CF}$ (Figure 1B) clearly show the rod-like morphology of $\mathrm{Cu}-\mathrm{MOF}$. The $\mathrm{Cu}-\mathrm{MOF}$ nanorod arrays are completely and uniformly covered on the 

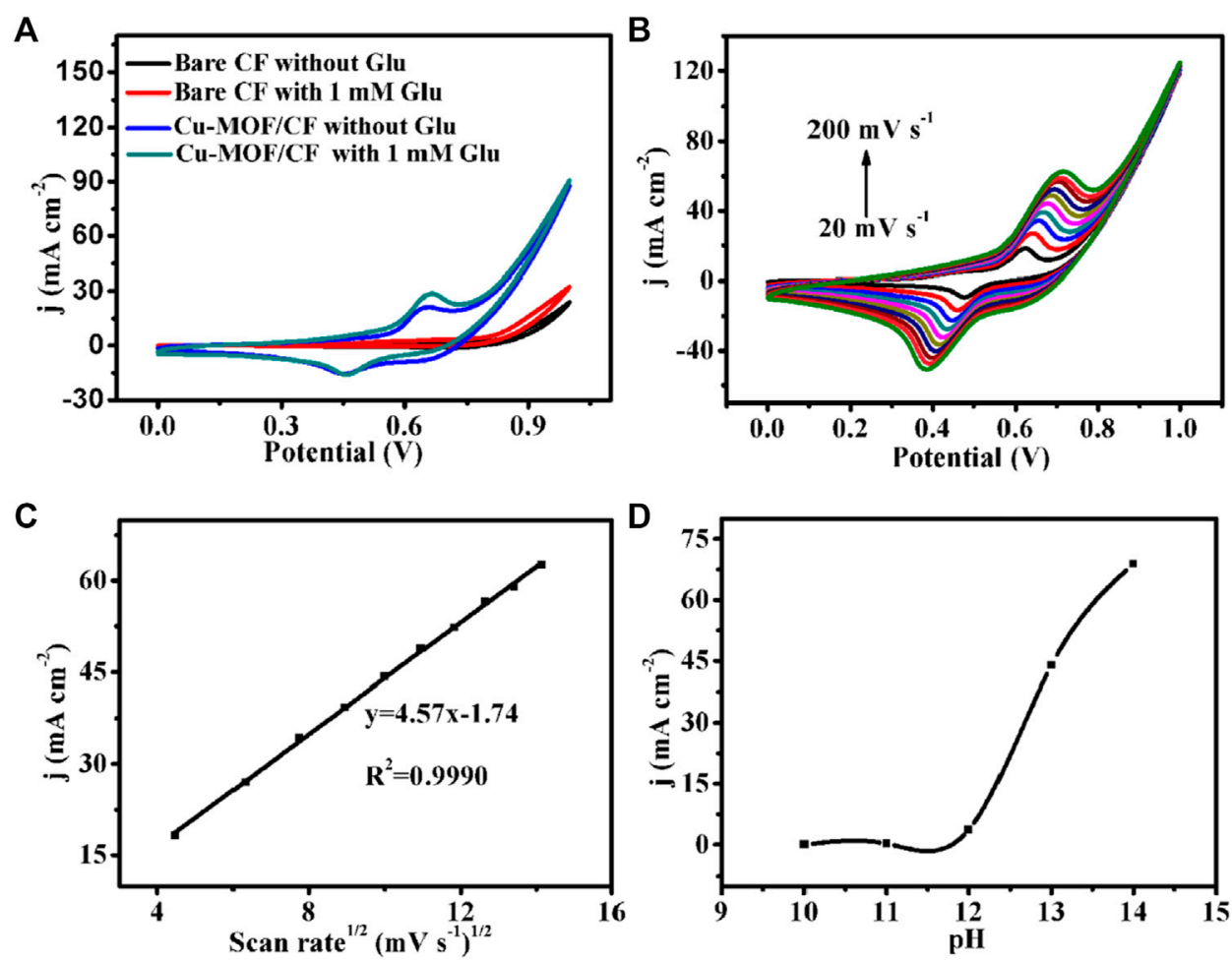

FIGURE 3 | (A) CVs of bare CF and Cu-MOF/CF in $0.1 \mathrm{M} \mathrm{NaOH}$ in the absence and presence of $1 \mathrm{mM} \mathrm{Glu} \mathrm{(scan} \mathrm{rate:} 50 \mathrm{mV} \mathrm{s}^{-1}$ ). (B) CVs for Cu-MOF/CF in $1 \mathrm{mM}$ Glu at scan rates from 20 to $200 \mathrm{mV} \mathrm{s}^{-1}$. (C) Corresponding plot of current density vs. the square root of the scan rate. (D) Plot of anodic peak current density vs pH for the Cu-MOF/CF electrode in the presence of $1 \mathrm{mM}$ glucose at $0.65 \mathrm{~V}$ (scan rate, $50 \mathrm{mV} \mathrm{s}^{-1}$ ).

CF (Figure 1D). The powder X-ray diffraction (PXRD) spectra can be used to confirm the structural identity and phase purity of the synthesized materials. Because the intensity of the diffraction peak of PXRD of $\mathrm{Cu}-\mathrm{MOF} / \mathrm{CF}$ is too weak (Supplementary Figure S1), the PXRD of the Cu-MOF powder collected from the reaction system was used to further confirm structural identity and phase purity of the synthetic materials (Figure 1C). The significant peaks at $2 \theta=4.6^{\circ}, 9.4^{\circ}, 12.4^{\circ}$, and $16.39^{\circ}$ correspond to (100), (200), (130), and (201) planes, respectively (Ko et al., 2018; Hoppe et al., 2018; Qiao et al., 2020). The visible peaks at $2 \theta=27.78^{\circ}$ could be attributed to the (002) plane (Hmadeh et al., 2012; Li et al., 2019; Wu et al., 2019). The XRD spectrum shows that $\mathrm{Cu}-\mathrm{MOF}$ has been successfully synthesized. The SEM image of $\mathrm{Cu}-\mathrm{MOF} / \mathrm{CF}$ and the corresponding energy-dispersive X-ray (EDX) element mapping image demonstrate the presence and homogeneous distributions on the bare $\mathrm{CF}$ of $\mathrm{C}, \mathrm{O}$, and $\mathrm{Cu}$ elements (Figure 1D). The corresponding energy-dispersive spectroscopy (EDS) further proves the presence of $\mathrm{C}, \mathrm{O}$, and $\mathrm{Cu}$ elements on the bare CF (Supplementary Figure S2). The elemental states and composition of $\mathrm{Cu}-\mathrm{MOF}$ were studied by XPS. The full spectrum of XPS reveals the existence of $\mathrm{C}, \mathrm{O}$, and $\mathrm{Cu}$ elements in $\mathrm{Cu}-\mathrm{MOF}$, which corresponds with EDX (Figure 2A). The XPS peaks of $\mathrm{C}$ 1s can be observed at 283.98, and $287.72 \mathrm{eV}$ (Figure 2B), which are composed of C-O and C-C, respectively (Jin et al., 2006; Yan et al., 2010;
Tian et al., 2017). In the $\mathrm{O} 1 \mathrm{~s}$ spectrum (Figure 2C), there are two $\mathrm{O}$ species, namely, $\mathrm{O}-\mathrm{Cu}$ at $530.42 \mathrm{eV}$ and $\mathrm{O}-\mathrm{H}$ at $532.48 \mathrm{eV}$ (Yang et al., 2020). As shown in Figure 2D, the main peaks at 932.47 and $952.58 \mathrm{eV}$ in the $\mathrm{Cu} 2 \mathrm{p}$ spectrum are assigned to $\mathrm{Cu}$ $2 \mathrm{p}_{3 / 2}$ and $\mathrm{Cu} 2 \mathrm{p}_{1 / 2}$ spin-orbit states, respectively, which indicates the $\mathrm{Cu}^{2+}$ state in the $\mathrm{Cu}-\mathrm{MOF}$ (He et al., 2016). The satellite peaks of $\mathrm{Cu}^{2+}$ can also be observed at 939.51, 943.84, and 962.24 eV (Liu et al., 2013; Tian et al., 2017).

\section{Electrochemical Characterizations}

In order to investigate the electrocatalytic performance of the as-prepared catalyst for glucose oxidation under alkaline $\mathrm{pH}$ conditions, electrochemical tests were carried out using a typical three-electrode setup in $0.1 \mathrm{M} \mathrm{NaOH}$. The cyclic voltammograms (CVs) were performed at a scan rate of 50 $\mathrm{mV} \mathrm{s}^{-1}$ within the potential range of $0-1 \mathrm{~V}$ (Figure 3A). The bare CF did not show any visible redox peak in the absence or presence of glucose, indicating no catalytic activity of the bare $\mathrm{CF}$ for glucose. $\mathrm{Cu}-\mathrm{MOF} / \mathrm{CF}$ displayed a reversible oxidation and reduction wave, confirming redox activity and providing the possibility for electrochemical sensing. A significant enhancement of the oxidation current was observed on the addition of $1 \mathrm{mM}$ glucose solution into the electrolyte, indicating that the $\mathrm{Cu}-\mathrm{MOF} / \mathrm{CF}$ has electrocatalytic activity for glucose oxidation. The possible corresponding reaction process of the as-prepared sensor for glucose oxidation can 

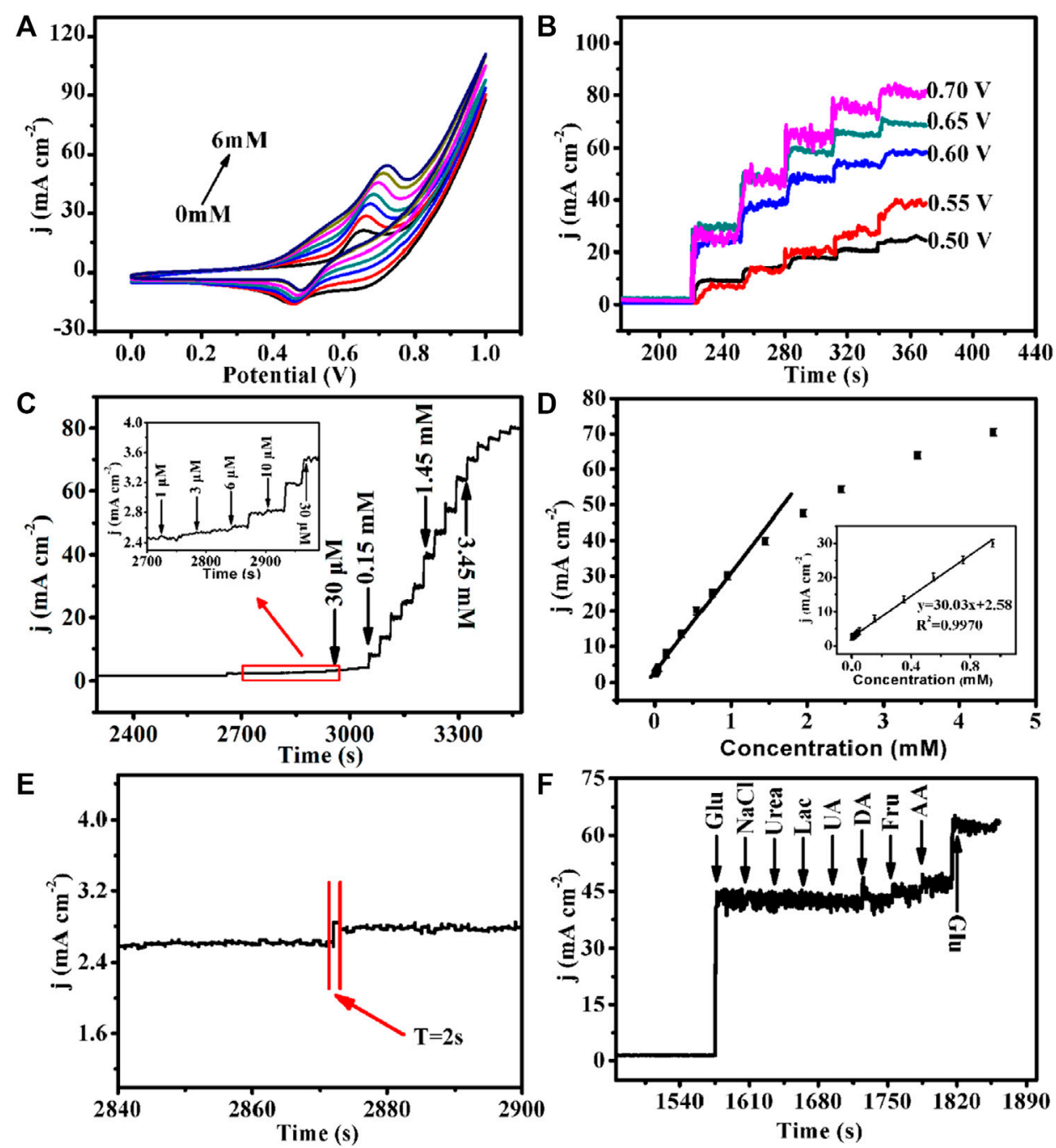

FIGURE 4 | (A) Cu-MOF/CF in $0.1 \mathrm{M} \mathrm{NaOH}$ with the presence of varied Glu concentrations: 0, 1, 2, 3, 4, 5, and 6 mM (from inner to outer) at a scan rate of $50 \mathrm{mVs}{ }^{-1}$. (B) Amperometric responses of the Cu-MOF/CF electrode at different potentials (from 0.50 to $0.7 \mathrm{~V}$ ) with continuous addition of $1 \mathrm{mM}$ Glu in $0.1 \mathrm{M}$ NaOH. (C) Amperometric response of Cu-MOF/CF with successive addition of Glu in $0.1 \mathrm{M} \mathrm{NaOH}$ (inset: the current response of the electrode toward the addition of Glu from $1 \mu \mathrm{M}$ to $30 \mu \mathrm{M}$ ) and (D) Corresponding calibration curve of Cu-MOF/CF electrode to successive additions of Glu at $0.65 \mathrm{~V}$ in $0.1 \mathrm{M} \mathrm{NaOH}$. (E) Amplification of the Cu-MOF/CF amperometric response curve. (F) Amperometric response of the $\mathrm{Cu}-\mathrm{MOF} / \mathrm{CF}$ electrode toward the addition of Glu (1 mM) with various interfering species (1 $\mathrm{mM})$ in $0.1 \mathrm{M} \mathrm{NaOH}$.

be predicted as follows (Lan et al., 2020; Pa et al., 2020; Zheng et al., 2020):

$$
\mathrm{Cu}(\mathrm{II})-\mathrm{MOF} / \mathrm{CF}+\mathrm{OH}^{-} \rightarrow \mathrm{Cu}(\mathrm{III})-\mathrm{MOF} / \mathrm{CF}+\mathrm{e}^{-}+\mathrm{H}_{2} \mathrm{O}
$$

$$
\begin{aligned}
\mathrm{Cu}(\mathrm{III})-\mathrm{MOF} / \mathrm{CF}+\text { Glucose } & \rightarrow \mathrm{Cu}(\mathrm{II})-\mathrm{MOF} / \mathrm{CF} \\
& + \text { Gluconolactone },
\end{aligned}
$$

Gluconolactone $+\mathrm{H}_{2} \mathrm{O} \rightarrow \mathrm{H}^{+}+$Gluconate.

In order to study the electrochemical process of glucose, the $\mathrm{CVs}$ of $\mathrm{Cu}-\mathrm{MOF} / \mathrm{CF}$ in $0.1 \mathrm{M} \mathrm{NaOH}$ with $1 \mathrm{mM}$ glucose were recorded at different scan rates from $20 \mathrm{mV} \mathrm{s}^{-1}$ to $200 \mathrm{mV} \mathrm{s}^{-1}$ (Figure 3B). As depicted in Figure 3C, the oxidation peak and reduction peak current densities increase with increasing scan rates. The oxidation peak currents are directly proportional to the square root of the scan rate in the rage of $20-200 \mathrm{mV}$, suggesting that the electrochemical oxidation process of glucose at the working electrode is diffuse-controlled (Zhu et al., 2018). Meanwhile, the oxidation peak moves to a more positive potential, and the reduction peak moves to a more negative potential (Karikalan et al., 2016). The electrochemical response of $\mathrm{Cu}-\mathrm{MOF} / \mathrm{CF}$ to $1 \mathrm{mM}$ glucose under different $\mathrm{pH}$ conditions was evaluated in an electrolyte containing $1 \mathrm{mM}$ glucose at $\mathrm{pH}$ values of 10-14 (Figure 3D). The peak current density of the oxidation peak increases with the increase in $\mathrm{pH}$ value. However, the oxygen evolution reaction at $\mathrm{pH} 14$ can cause a sharp increase in the catalytic current density which can interfere with glucose detection. Therefore, $\mathrm{pH} 13$ was chosen as the optimal $\mathrm{pH}$ value for follow-up experiments in this study. 


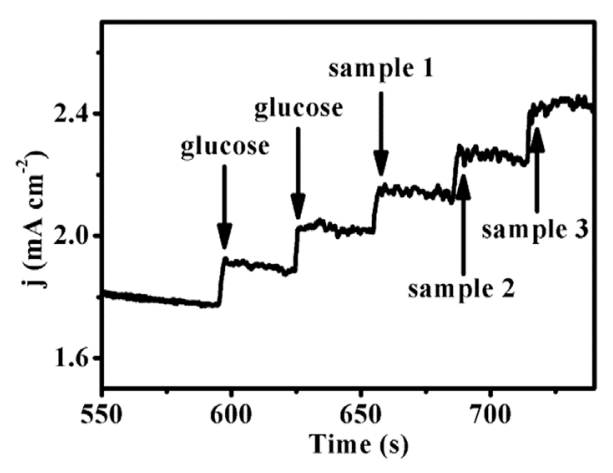

FIGURE 5 | Amperometric response of the Cu-MOF/CF with addition of glucose and three serum samples (glucose: $5 \mathrm{mM}$, potential: $0.65 \mathrm{~V}$, solution: $0.1 \mathrm{M} \mathrm{NaOH})$.

Moreover, the $\mathrm{CV}$ curves of $\mathrm{Cu}-\mathrm{MOF} / \mathrm{CF}$ with glucose concentration from 0 to $6 \mathrm{mM}$ were tested to further study the electrochemical performance. As shown in Figure 4A, when the concentration of glucose increases, the anodic current density increases and the anodic oxidation peak shifts to the corrected position, demonstrating superior electrocatalytic activity. In order to find the optimal voltage for the detection, at a fixed scanning rate, glucose $(1 \mathrm{mM})$ was successively added to the $\mathrm{NaOH}(0.1 \mathrm{M})$ electrolyte at voltages of $+0.5,+0.55,+0.6,+0.65$, and $+0.7 \mathrm{~V}$ (Figure 4B). The five potentials exhibit similar current responses. The current density increases with the increase in the working potential and reaches the maximum at $+0.7 \mathrm{~V}$. Compared with +0.7 $\mathrm{V},+0.65 \mathrm{~V}$ exhibits relatively small noise on the current, so it was chosen as the optimal voltage for further tests. Under the optimal voltage $(+0.65 \mathrm{~V})$, glucose solutions of different concentrations and volumes to the $\mathrm{NaOH}(0.1 \mathrm{M})$ electrolyte were used to make the glucose concentration in the electrolyte continuously change to obtain the final current-time diagram (Figure 4C). The amperometric responses of $\mathrm{Cu}-\mathrm{MOF} / \mathrm{CF}$ on different concentrations of glucose were recorded by successively adding different concentrations and volumes of glucose to the electrolyte, with concentrations ranging from $1 \mathrm{uM}$ to $3.45 \mathrm{mM}$ under constant stirring (Figure 4C). The anode current increases obviously with the addition of glucose. Figure 4D illustrates the relationship between glucose concentration and current response signal. The current density and glucose concentration have a linear relationship within the range of $0.001-0.95 \mathrm{mM}$. The corresponding linear equation is $\mathrm{j}\left(\mathrm{mA} \mathrm{cm}{ }^{-2}\right)=30.03 \mathrm{c}+2.58\left(R^{2}=0.997\right)$, and the sensitivity was $30,030 \mathrm{~mA} \mu \mathrm{M}^{-1} \mathrm{~cm}^{-2}$. According to the 3-fold signal/noise value $(\mathrm{S} / \mathrm{N}=3$ ) (Zhou et al., 2020), the limit of detection (LOD) was $0.076 \mu \mathrm{M}$. Meanwhile, it takes only 2 s to reach a steadystate current density from one concentration to an adjacent high concentration, which reveals that the prepared $\mathrm{Cu}-\mathrm{MOF} / \mathrm{CF}$ electrode has a fast ampere response to glucose (Figure 4E). All the results show that $\mathrm{Cu}-\mathrm{MOF} / \mathrm{CF}$ exhibits better electrocatalytic performance with rather high sensitivity, low LOD, and wide detection range than most reported non-enzymatic sensors (Supplementary Table S1) and provided a promising prospect for MOF-based materials as glucose sensors. For biological systems, glucose often coexists with biological molecules, such as ascorbic acid, urea, uric acid, $\mathrm{NaCl}$, and dopamine, and some other sugar molecules such as lactose and fructose which may disturb the detection of glucose. So, the anti-interference tests are essential. In

TABLE 1 | Sensor in this study and the blood glucose meter test on serum samples $(n=3)$.

\begin{tabular}{|c|c|c|c|c|}
\hline Sample & $\begin{array}{l}\text { Measured } \\
\text { by glucometer }(\mathrm{mM})\end{array}$ & $\begin{array}{l}\text { Determined by the sensor } \\
\text { (mM) }\end{array}$ & SD & RSD (\%) \\
\hline 1 & 4.8 & 5.09 & 0.16 & 3.25 \\
\hline 2 & 5.2 & 5.13 & 0.08 & 1.48 \\
\hline 3 & 6.4 & 6.64 & 0.22 & 3.44 \\
\hline
\end{tabular}

All the concentration tests and RSD calculations are of three independent measurements. SD, standard deviation; RSD, relative standard deviations.
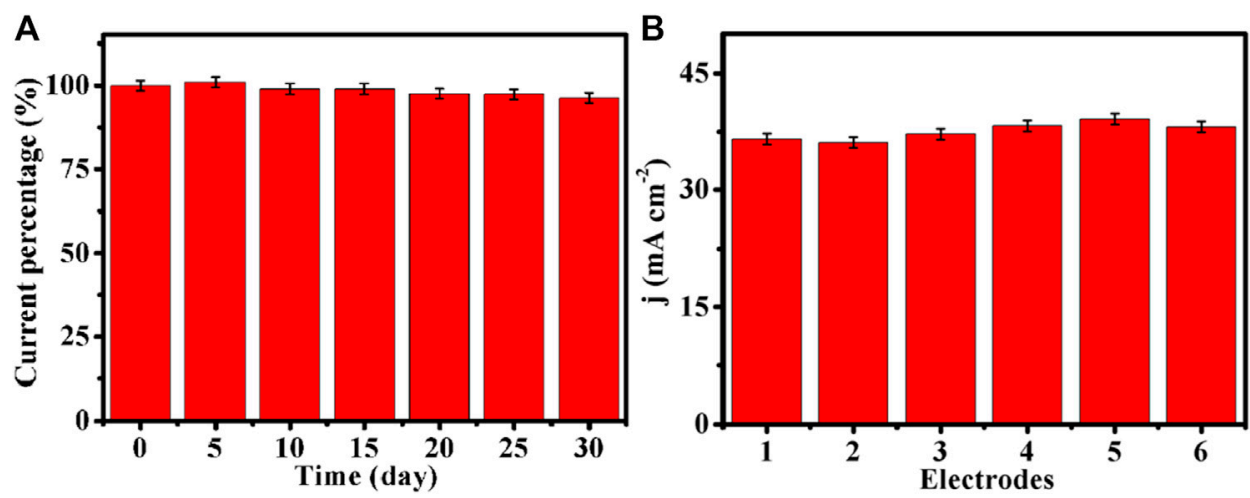

FIGURE 6 | (A) Stability of Cu-MOF/CF to $1 \mathrm{mM}$ glucose tested every 7 days by cyclic voltammetry in 1 month. (B) Reproducibility of six biosensors toward $1 \mathrm{mM}$ glucose in $0.1 \mathrm{M} \mathrm{NaOH}$. 
order to study the selectivity of the prepared $\mathrm{Cu}-\mathrm{MOF} / \mathrm{CF}$, we conducted anti-interference tests by recording the current responses with adding the aforementioned interferences in the electrolyte. As shown in Figure 4F, a salient signal appeared on adding glucose, but with the addition of other interfering substances (0.1 mM lactose (Lac), $0.1 \mathrm{mM}$ fructose (Fru), $0.1 \mathrm{mM}$ ascorbic acid (AA), $1 \mathrm{mM}$ urea (UR), $0.1 \mathrm{mM}$ uric acid (UA), $1 \mathrm{mM} \mathrm{NaCl}$, and $0.1 \mathrm{mM}$ dopamine (DA)), no obvious signal could be observed. Considering that the concentration of glucose in the physiological environment is more than 30 times that of interfering substances, the $\mathrm{Cu}-\mathrm{MOF} / \mathrm{CF}$ with good selectivity has strong practical application feasibility.

In order to verify the practical application feasibility of the sensor, $\mathrm{Cu}-\mathrm{MOF} / \mathrm{CF}$ was used to determine the glucose concentration in human serum samples at $0.65 \mathrm{~V}$. Three blood samples were tested. The ampere-current responses of the serum sample are shown in Figure 5. And the measured values were almost on a par with the value from the commercial glucometer. The standard deviations and the relative standard deviation (RSD) were less than 0.22 and $3.44 \%$, respectively (Table 1). The aforementioned results show that this method is accurate and reliable. Therefore, the sensor can provide an effective method for the determination of glucose in practical samples.

Stability is also a critical parameter for practical applications of sensors. The long-term stability experiments of $\mathrm{Cu}-\mathrm{MOF} / \mathrm{CF}$ were carried out every 7 days by cyclic voltammetry in 1 month. As shown in Figure 6A, the current density can retain $96 \%$ of initial catalytic activity after a month of stability tests, indicating good stability of $\mathrm{Cu}-\mathrm{MOF} / \mathrm{CF}$. In order to investigate the reproducibility of the electrodes, six $\mathrm{Cu}-\mathrm{MOF} / \mathrm{CF}$ electrodes were prepared separately under the same conditions. Glucose oxidation was tested at six independent sensors (Figure 6B). The $\mathrm{SD}$ and RSD of the six electrodes to $1 \mathrm{mM}$ glucose current were about 1.15 and 3\%, respectively (Supplementary Table S2), indicating noticeable reproducibility.

\section{CONCLUSION}

In summary, without using any polymer binder, the conductive $\mathrm{Cu}$ MOF was successfully grown on the CF by the one-step hydrothermal method and could act as an effective catalyst electrode for the electrochemical oxidation of glucose under alkaline conditions. As

\section{REFERENCES}

Adil, K., Belmabkhout, Y., Pillai, R. S., Cadiau, A., Bhatt, P. M., Assen, A. H., et al. (2017). Gas/Vapour Separation Using Ultra-Microporous Metal-Organic Frameworks: Insights Into the Structure/Separation Relationship. Chem. Soc. Rev. 46, 3402-3430. doi:10.1039/c7cs00153c

Archana, V., Xia, Y., Fang, R., and Gnana Kumar, G. (2019). Hierarchical CuO/NiOCarbon Nanocomposite Derived From Metal Organic Framework on Cello Tape for the Flexible and High Performance Nonenzymatic Electrochemical Glucose Sensors. ACS Sust. Chem. Eng. 7, 6707-6719. doi:10.1021/acssuschemeng.8b05980

Chandran, G. T., Li, X., Ogata, A., and Penner, R. M. (2017). Electrically Transduced Sensors Based on Nanomaterials (2012-2016). Anal. Chem. 89, 249-275. doi:10.1021/acs.analchem.6b04687 a high-efficiency electrochemical sensor for non-enzymatic glucose detection, the material exhibits excellent catalyst performance with a short response time ( $2 \mathrm{~s})$, a wide detection range (0.001-0.95 mM), a low detection limit $(0.076 \mu \mathrm{M}, \mathrm{S} / \mathrm{N}=3)$, strong sensitivity $(30,030$ $\mathrm{mA} \mu \mathrm{M}^{-1} \mathrm{~cm}^{-2}$ ), and good stability and repeatability. This study not only demonstrates excellent performance of MOF-based materials and their potential as a promising platform for the fabrication of highly sensitive electrochemical biosensors but also provides an attractive, cost-effective, easily prepared electrode material for efficient glucose detection.

\section{DATA AVAILABILITY STATEMENT}

The original contributions presented in the study are included in the article/Supplementary Material; further inquiries can be directed to the corresponding authors.

\section{AUTHOR CONTRIBUTIONS}

HW and GL contributed to the conception and design of the study. QH synthesized the material. QH and GR organized the database. QH and QW performed the statistical analysis. QH wrote the first draft of the manuscript. JQ, XW, JM, and JG wrote sections of the manuscript. JM conducted some measurements and data analysis. All authors contributed to manuscript revision and read and approved the submitted version.

\section{FUNDING}

This study was supported by the National Natural Science Foundation (Nos. 21801127, 21771120, 21671107, 21801054, and 21301108) and financial support from the State Key Laboratory of Coordination Chemistry, Nanjing University (SKLCC1908).

\section{SUPPLEMENTARY MATERIAL}

The Supplementary Material for this article can be found online at: https:/www.frontiersin.org/articles/10.3389/fchem.2021.786970/ full\#supplementary-material

Cheng, C., Zheng, F., Zhang, C., Du, C., Fang, Z., Zhang, Z., et al. (2019). HighEfficiency Bifunctional Electrocatalyst Based on 3D Freestanding $\mathrm{Cu}$ Foam In Situ Armored Coni Alloy Nanosheet Arrays for Overall Water Splitting. J. Power Sourc. 427, 184-193. doi:10.1016/j.jpowsour.2019.04.071

Clark, L. C., and Lyons, C. (2010). Electrode Systems for Continuous Monitoring in Cardiovascular Surgery. Ann. N. Y. Acad. Sci. 102, 29-45. doi:10.1111/j.17496632.1962.tb13623.x

Doonan, C., Riccò, R., Liang, K., Bradshaw, D., and Falcaro, P. (2017). MetalOrganic Frameworks at the Biointerface: Synthetic Strategies and Applications. Acc. Chem. Res. 50, 1423-1432. doi:10.1021/acs.accounts.7b00090

Feng, H., Huang, Z., Lou, X., Li, J., and Hui, G. (2016). Study of a Sucrose Sensor by Functional $\mathrm{Cu}$ Foam Material and its Applications in Commercial Beverages. Food Anal. Methods. 10, 407-418. doi:10.1007/s12161-0160580-9 
He, J., Yang, H., Zhang, Y., Yu, J., Miao, L., Song, Y., et al. (2016). Smart Nanocomposites of $\mathrm{Cu}$-Hemin Metal-Organic Frameworks for Electrochemical Glucose Biosensing. Sci. Rep. 6, 36637. doi:10.1038/srep36637

Hmadeh, M., Lu, Z., Liu, Z., Gándara, F., Furukawa, H., Wan, S., et al. (2012). New Porous Crystals of Extended Metal-Catecholates. Chem. Mater. 24, 3511-3513. doi:10.1021/cm301194a

Hoppe, B., Hindricks, K. D. J., Warwas, D. P., Schulze, H. A., Mohmeyer, A., Pinkvos, T. J., et al. (2018). Graphene-Like Metal-Organic Frameworks: Morphology Control, Optimization of Thin Film Electrical Conductivity and Fast Sensing Applications. CrystEngComm. 20, 6458-6471. doi:10.1039/ c8ce01264d

Hou, Y.-L., Xiong, G., Shi, P.-F., Cheng, R.-R., Cui, J.-Z., and Zhao, B. (2013). Unique $(3,12)$-Connected Coordination Polymers Displaying High Stability, Large Magnetocaloric Effect and Slow Magnetic Relaxation. Chem. Commun. 49, 6066-6068. doi:10.1039/c3cc42545b

Hu, Z., Miao, Y., Xue, X., Xiao, B., Qi, J., Wei, F., et al. 2021).CuO@NiCoFe-S CoreShell Nanorod Arrays Based on Cu Foam for High Performance Energy Storage. J. Colloid Interf. Sci. 599, 34-45. doi:10.1016/j.jcis.2021.04.085

Hua, Z., Li, L., Wei, Z., Shao, Z., and Chen, X. (2016). Advances in Non-Enzymatic Glucose Sensors Based on Metal Oxides. J. Mater. Chem. B. 5, 7333-7349. doi:10.1039/C6TB02037B

Hui, G. H., Lu, H. Y., Jiang, Z. M., Zhu, D. H., and Wan, H. F. (2017). Study of Small-Cell Lung Cancer Cell-Based Sensor and its Applications in Chemotherapy Effects Rapid Evaluation for Anticancer Drugs. Biosens. Bioelectron. 97, 184-195. doi:10.1016/j.bios.2017.05.050

Hui, G., and Ying, Y. (2017). Quantitative Rapid Analysis Method for Ofloxacin in Raw Milk Based on Molecule-Specific Recognition and Electrochemical Impedance Spectrum. Trans. ASABE. 60, 1439-1443. doi:10.13031/trans.11465

Hui, G., Zhang, J., Li, J., and Zheng, L. (2016). Sucrose Quantitative and Qualitative Analysis from Tastant Mixtures Based on $\mathrm{Cu}$ Foam Electrode and Stochastic Resonance. Food Chem. 197, 1168-1176. doi:10.1016/j.foodchem.2015.11.091

Jin, A. K., Dong, G. S., Kang, T. J., and Youn, J. R. (2006). Effects of Surface Modification on Rheological and Mechanical Properties of CNT/Epoxy Composites. Carbon. 44, 1898-1905. doi:10.1016/j.carbon.2006.02.026

Kanj, A. B., Verma, R., Liu, M., Helfferich, J., Wenzel, W., and Heinke, L. (2019). Bunching and Immobilization of Ionic Liquids in Nanoporous Metal-Organic Framework. Nano Lette. 19, 2114-2120. doi:10.1021/acs.nanolett.8b04694

Karikalan, N., Velmurugan, M., Chen, S.-M., and Karuppiah, C. (2016). Modern Approach to the Synthesis of $\mathrm{Ni}(\mathrm{OH}) 2$ Decorated Sulfur Doped Carbon Nanoparticles for the Nonenzymatic Glucose Sensor. ACS Appl. Mater. Inter. 8, 22545-22553. doi:10.1021/acsami.6b07260

Ko, M., Mendecki, L., and Mirica, K. A. (2018). Conductive Two-Dimensional Metal-Organic Frameworks as Multifunctional Materials. Chem. Commun. 54, 7873-7891. doi:10.1039/c8cc02871k

Lan, W. U., Zhi-Wei, L. U., Ying, M. A., Zhang, J. J., Guang, Q. M., and Hai, J. D. (2020). $\mathrm{Cu}(\mathrm{II})$ Metal-Organic Framework Encapsulated in Carbon Paste Electrode for High-Performance Non-Enzymatic Glucose Sensing. Chin. J. Anal. Chem. 48, e20038-e20046. doi:10.1016/S1872-2040(20)60006-8

Larsen, T. (2015). Fluorometric Determination of Free Glucose and Glucose 6phosphate in Cows' Milk and Other Opaque Matrices. Food Chem. 166, 283-286. doi:10.1016/j.foodchem.2014.06.017

Li, T., Zhang, W.-D., Liu, Y., Li, Y., Cheng, C., Zhu, H., et al. (2019). A TwoDimensional Semiconducting Covalent Organic Framework with Nickel(II) Coordination for High Capacitive Performance. J. Mater. Chem. A. 7, 19676-19681. doi:10.1039/c9ta07194f

Liu, S., Tian, J., Lei, W., Luo, Y., and Sun, X. (2011). A General Strategy for the Production of Photoluminescent Carbon Nitride Dots From Organic Amines and Their Application as Novel Peroxidase-Like Catalysts for Colorimetric Detection of $\mathrm{H}_{2} \mathrm{O}_{2}$ and Glucose. Rsc Adv. 2, 411-413. 10. 1039/C1RA00709B

Liu, Y., Cao, X., Cui, L., Zhong, Y., Zheng, R., Wei, D., et al. (2019). Zn-Ni-Co Trimetallic Carbonate Hydroxide Nanothorns Branched on $\mathrm{Cu}(\mathrm{OH}) 2$ Nanorods Array Based on $\mathrm{Cu}$ Foam for High-Performance Asymmetric Supercapacitors. J. Power Sourc. 437, 226897. doi:10.1016/ j.jpowsour.2019.226897

Liu, Y., Wang, W., Gu, L., Wang, Y., Ying, Y., Mao, Y., et al. (2013). Flexible Cuo Nanosheets/Reduced-Graphene Oxide Composite Paper: Binder-Free Anode for High-Performance Lithium-Ion Batteries. ACS Appl. Mater. Inter. 5, 9850-9855. doi:10.1021/am403136e

Lpa, B., Ss, A., Sa, A., Vu, C., and Ssk, D. (2019). A non-Enzymatic Electrochemical Sensor Based on zro 2: $\mathrm{Cu}(\mathrm{I})$ Nanosphere Modified Carbon Paste Electrode for Electro-Catalytic Oxidative Detection of Glucose in raw Citrus Aurantium var. Sinensis. Food Chem. 125178, 1. 10.1016/j.foodchem.2019.125178

Niu, X., Li, X., Pan, J., He, Y., Qiu, F., and Yan, Y. 2016). Recent Advances in NonEnzymatic Electrochemical Glucose Sensors Based on Non-Precious Transition Metal Materials: Opportunities and Challenges. RSC Adv. 6, 84893-84905. doi:10.1039/c6ra12506a

Pa, A., Nskg, A., Saj, A., and Mt, B. (2020). Tunable Electrochemical Synthesis of 3D Nucleated Microparticles Like Cu-BTC MOF-Carbon Nanotubes Composite: Enzyme Free Ultrasensitive Determination of Glucose in a Complex Biological Fluid. Electrochimica Acta. 354, 136673. doi:10.1016/ j.electacta.2020.136673

Pandey, A., Tripathi, P., Pandey, R., Srivatava, R., and Goswami, S. (2011). Alternative Therapies Useful in the Management of Diabetes: a Systematic Review. J. Pharm. Bioallied Sci. 3, 504-512. doi:10.4103/0975-7406.90103

Qiao, Y., Liu, Q., Lu, S., Chen, G., Gao, S., Lu, W., et al. 2020). High-Performance Non-Enzymatic Glucose Detection: Using a Conductive Ni-MOF as an Electrocatalyst. J. Mater. Chem. B 8, 5411-5415. doi:10.1039/d0tb00131g

Shi, Y., Momeni, M. R., Chen, Y.-J., Zhang, Z., and Shakib, F. A. (2020). WaterInduced Structural Transformations in Flexible Two-Dimensional Layered Conductive Metal-Organic Frameworks. Chem. Mater. 32, 9664-9674. doi:10.1021/acs.chemmater.0c03331

Stassen, I., Burtch, N., Talin, A., Falcaro, P., Allendorf, M., and Ameloot, R. (2017). An Updated Roadmap for the Integration of Metal-Organic Frameworks With Electronic Devices and Chemical Sensors. Chem. Soc. Rev. 46, 3185-3241. doi: $10.1039 / \mathrm{c} 7 \mathrm{cs} 00122 \mathrm{c}$

Su, J., Yuan, S., Wang, H.-Y., Huang, L., Ge, J.-Y., Joseph, E., et al. (2017). Redoxswitchable Breathing Behavior in Tetrathiafulvalene-Based Metal-Organic Frameworks. Nat. Commun. 8, 2008. doi:10.1038/s41467-017-02256-y

Tian, P., Liu, D., Li, K., Yang, T., Wang, J., Liu, Y., et al. (2017). Porous MetalOrganic Framework Cu3(BTC)2 as Catalyst Used in Air-Cathode for High Performance of Microbial Fuel Cell. Bioresour. Tech. 244, 206-212. doi:10.1016/ j.biortech.2017.07.034

Usman, M., Mendiratta, S., and Lu, K.-L. (2016). Semiconductor Metal-Organic Frameworks: Future Low-Bandgap Materials. Adv. Mater. 29, 1605071. doi:10.1002/adma.201605071

Wang, C., Liu, D., and Lin, W. (2013). Metal-Organic Frameworks as a Tunable Platform for Designing Functional Molecular Materials. J. Am. Chem. Soc. 135, 13222, 13234. doi:10.1021/ja308229p

Wang, Q., Xu, Z., Zhao, Y., Hui, Z., Bu, T., Zhang, C., et al. (2020). Bio-Inspired Self-Cleaning Carbon Cloth Based on Flower-like Ag Nanoparticles and LeafLike Mof: a High-Performance and Reusable Substrate for Sers Detection of Azo Dyes in Soft Drinks - Sciencedirect. Sens. Actuators B Chem. 329, 1290801. doi:10.1016/j.snb.2020.129080

Wang, T., Jin, R., Wu, Y., Zheng, J., and Li, X. (2018). Chemical Induced Fragmentation of MOFs for Highly Efficient Ni-Based Hydrogen Evolution Catalysts. Nanoscale Horiz. 3, 218-225. doi:10.1039/c7nh00193b

Wei, L., and Yin, X. B. (2015). Metal Organic Frameworks for Electrochemical Applications. Trac Trends Analyt. Chem. 5, 9269. doi:10.1039/C2EE22989G

Wu, H., Zhang, W., Kandambeth, S., Shekhah, O., Eddaoudi, M., and Alshareef, H. N. (2019). Conductive Metal-Organic Frameworks Selectively Grown on LaserScribed Graphene for Electrochemical Microsupercapacitors. Adv. Energ. Mater. 9, 1900482. doi:10.1002/aenm.201900482

Xie, W.-Q., Gong, Y.-X., and Yu, K.-X. (2017). Rapid Quantitative Detection of Glucose Content in Glucose Injection by Reaction Headspace Gas Chromatography. J. Chromatogr. A. 1520, 143-146. doi:10.1016/ j.chroma.2017.09.018

Xu, Z., Wang, Q., Zhangsun, H., Zhao, S., Zhao, Y., and Wang, L. (2021). Carbon Cloth-Supported Nanorod-Like Conductive Ni/Co Bimetal Mof: a Stable and High-Performance Enzyme-Free Electrochemical Sensor for Determination of Glucose in Serum and Beverage. Food Chem. 349, 129202. doi:10.1016/ j.foodchem.2021.129202

Yan, J., Wei, T., Shao, B., Ma, F., Fan, Z., Zhang, M., et al. (2010). Electrochemical Properties of Graphene Nanosheet/Carbon Black 
Composites as Electrodes for Supercapacitors. Carbon. 48, 1731-1737. doi:10.1016/j.carbon.2010.01.014

Yang, W., Cheng, M., Han, Y., Luo, X., Li, C., Tang, W., et al. 2020). Heavy Metal Ions' Poisoning Behavior-Inspired Etched UiO-66/CTS Aerogel for $\mathrm{Pb}(\mathrm{II})$ and Cd(II) Removal from Aqueous and Apple Juice. J. Hazard. Mater. 401, 123318. doi:10.1016/j.jhazmat.2020.123318

Zhang, X. H., Zhao, Z. D., Lou, X. W., Li, J., and Hui, G. H. (2017). A Maltose, L-Rhamnose Sensor Based on Porous $\mathrm{Cu}$ Foam and Electrochemical Amperometric I-T Scanning Method. J. Food Meas. Charact. 11, 548-555. 10.1007/s11694-016-9422-0

Zhao, C., Wu, X., Zhang, X., Li, P., and Qian, X. (2017). Facile Synthesis of Layered $\mathrm{CuS} / \mathrm{RGO} / \mathrm{CuS}$ Nanocomposite on Cu Foam for Ultrasensitive Nonenzymatic Detection of Glucose. J. Electroanalytical Chem. 785, 172-179. doi:10.1016/ j.jelechem.2016.12.039

Zhao, T., Jeremias, F., Boldog, I., Nguyen, B., Henninger, S. K., and Janiak, C. (2015). High-Yield, Fluoride-Free and Large-Scale Synthesis of MIL-101(Cr). Dalton Trans. 44, 16791-16801. doi:10.1039/c5dt02625c

Zhao, Y., Zheng, X., Wang, Q., Zhe, T., Bai, Y., Bu, T., et al. (2020). Electrochemical Behavior of Reduced Graphene Oxide/Cyclodextrins Sensors for Ultrasensitive Detection of Imidacloprid in Brown rice. Food Chem. 333, 127495. doi:10.1016/ j.foodchem.2020.127495

Zheng, H., Ying, X., Wang, W., Chen, Z., Shao, C., Zhou, H., et al. (2019). Study of Sensitivity Evaluation on Ridgetail White Prawn (Exopalaemon Carinicauda) Quality Examination Methods. Int. J. Food Properties. 22, 942-951. doi:10.1080/ 10942912.2019.1617304

Zheng, W., Liu, Y., Yang, P., Chen, Y., Tao, J., Hu, J., et al. (2020). Carbon Nanohorns Enhanced Electrochemical Properties of Cu-Based Metal Organic Framework for Ultrasensitive Serum Glucose Sensing. J. Electroanalytical Chem. 862, 114018. doi:10.1016/j.jelechem.2020.114018

Zhou, Y., Hu, Q., Yu, F., Ran, G.-Y., Wang, H.-Y., Shepherd, N. D., et al. (2020). A Metal-Organic Framework Based on a Nickel Bis(dithiolene)
Connector: Synthesis, Crystal Structure, and Application as an Electrochemical Glucose Sensor. J. Am. Chem. Soc. 142, 20313-20317. doi:10.1021/jacs.0c09009

Zhu, W., Tang, C., Liu, D., Wang, J., Asiri, A. M., and Sun, X. (2016). A SelfStanding Nanoporous MoP2 Nanosheet Array: an Advanced pH-Universal Catalytic Electrode for the Hydrogen Evolution Reaction. J. Mater. Chem. A. 4, 7169-7173. doi:10.1039/c6ta01328g

Zhu, W., Wang, J., Zhang, W., Hu, N., Wang, J., Huang, L., et al. (2018). Monolithic Copper Selenide Submicron Particulate Film/copper Foam Anode Catalyst for Ultrasensitive Electrochemical Glucose Sensing in Human Blood Serum. J. Mater. Chem. B. 6, 718-724. doi:10.1039/c7tb02996a

Conflict of Interest: The authors declare that the research was conducted in the absence of any commercial or financial relationships that could be construed as a potential conflict of interest.

The handling editor declared a past co-authorship with one of the authors (JG).

Publisher's Note: All claims expressed in this article are solely those of the authors and do not necessarily represent those of their affiliated organizations or those of the publisher, the editors, and the reviewers. Any product that may be evaluated in this article, or claim that may be made by its manufacturer, is not guaranteed or endorsed by the publisher.

Copyright $\odot 2021 \mathrm{Hu}$, Qin, Wang, Ran, Wang, Liu, Ma, Ge and Wang. This is an open-access article distributed under the terms of the Creative Commons Attribution License (CC BY). The use, distribution or reproduction in other forums is permitted, provided the original author(s) and the copyright owner(s) are credited and that the original publication in this journal is cited, in accordance with accepted academic practice. No use, distribution or reproduction is permitted which does not comply with these terms. 